\title{
Operating Efficiency and its Effect from Innovative Teaching through Digital Mobile e-Learning for Public and Private High Schools
}

\author{
Hsiang-Hsi Liu ${ }^{1} \&$ Fu-Hsiang Kuo, ${ }^{2}$ * \\ ${ }^{1}$ Graduate Institute of International Business, National Taipei University, New Taipei City, \\ Taiwan \\ ${ }^{2}$ Department of Information Management, Chaoyang University of Technology, Taichung \\ City, Taiwan \\ *Correspondence: Department of Information Management, Chaoyang University of \\ Technology, Taichung City, Taiwan. E-mail: s1185072@gmail.com
}

Received: March 16, 2017 Accepted: March 21, 2017 Published: September 8, 2017

doi: 10.5296/rae.v9i3.11828 URL: https://doi.org/10.5296/rae.v9i3.11828

\begin{abstract}
The goal of this research is to evaluate the innovative teaching to affect school efficiency through using digital mobile e-learning of high school in Taiwan. Based on Data Envelopment Analysis (DEA) and Tobit regression model (TRM). The empirical results of this research indicate the following results: (1) Importing digital mobile e-learning can really enhance the efficiency of school management. (2) School size, teacher-student ratio, School High-Vocational attribute, especially the numbers of technical teachers in teaching or consulting about digital mobile e-learning knowledge and numbers of Tablet PC (proxy for digital mobile e-learning) to affect efficiency of school management. Therefore, in order to increase students learning effectiveness in school, it is necessary to first add school size, Tablet PC numbers and technical teachers. However, total equipment expenses associated with tablet PC has a small negative influence on school management efficiency due to the increasing costs for furnishing the related internet and network equipment or device facilitate for teaching and learning among teachers and students by digital mobile e-learning. The results of this research can also be the reference for educational authorities when formulating policies and regulations for promoting digital mobile e-learning.
\end{abstract}

Keywords: Operating Efficiency, Digital Mobile e-Learning, Data Envelopment Analysis (DEA), Tobit Regression Model (TRM), Vocational and Senior High School 


\section{Introduction}

The fast advancement of information technology and continuous improvement of mobile digital learning (such as smart phones, PDAs, and tablets) in recent years have contributed to a steady growth of software and hardware development for digital learning technology. Earlier, technology was incorporated into teaching merely as a supplemental tool. However, technology is playing a pivotal role in digital mobile e-learning today, and has allowed teachers to experience the importance and emerging trend of combining technology with instruction in the classroom. Hence, the Department of Education and the LearnMode Education Foundation in Taiwan have collaborated at the grassroots level to promote the combination of mobile technology and teaching to schools in various counties and cities in Taiwan. The aim being to help teachers and students in these institutions to develop better teaching experience by utilizing wireless networks or platforms like mobile applications, as well as to enhance the teaching in schools and increase students' interest in learning by utilizing mobile digital learning.

According to the digital opportunity survey of individual households in 2014 compiled by the National Development Council, the Internet usage of individuals from 2012 to 2014 increased for all counties and cities in Taiwan. However, there was still a difference of $20 \%$ between counties and cities. Further research on the development of digital opportunity in all regions of Taiwan in 2013 showed that more than $90 \%$ of the population in New Taipei City was connected to the Internet whereas only $72.5 \%$ of the population in the Hualien-Taitung region was connected. There remains a digital divide across regions in Taiwan.

On the other hand, Taiwan as well as other advanced economies are facing the challenge of low birth rate which also significantly impacts educational institutes, particularly in terms of how well schools are operated and the education quality that schools provide. Hence, schools need to change or transform the way in which they operate in order to increase schools' competitiveness. To drive student attendance, schools formulate their respective blue ocean strategies. Hence, the Department of Education collaborated with grassroots foundations in September, 2012 and donated 6,500 tablets first to the freshmen and teachers at six senior high schools in Taipei, in order to promote digital mobile e-learning by incorporating e-teaching platforms. By 2014, 45,000 tablets were donated to approximately 101 schools nationwide, which allowed students and teachers in various counties and cities to develop digital mobile e-learning by utilizing wireless networks to enhance teaching quality and increase students' interest level. Digital mobile e-learning has thus become a topic of interest to both the academics and the private sector. Public and private schools alike are striving to highlight their respective strengths and to increase their competitive advantages, meet students' and parents' needs, and establish unique attributes through innovative operations, so schools can win parents' and students' favorable consideration (Chiang, 2009).

In recent years, schools in various counties and cities in Taiwan have gradually introduced education reforms and innovative teaching such as mobile digital learning. A good deal of literature has reported that digital mobile e-learning can increase students' interest in learning as well as their motivation to learn. However, whether the high schools that have introduced 
mobile digital learning to enhance classroom teaching, increase in-classroom learning effectiveness, attracting student attendance, and in turn raising schools' operational efficiency remains a topic not yet widely addressed in the literature published domestically. Relevant theoretical foundations are likewise not widely. Hence, what prompted the undertaking of the current study was to better understand the actual teaching in the field by analyzing appropriate cases where schools have embarked on initiatives to improve themselves, and to derive suitable policy recommendations. Specifically, we firstly applies data envelopment analysis (DEA) to analyze the operational efficiency of high school in this study and justify whether mobile digital learning can affect a school's operational efficiency by Tobin regression model (TRM).

The paper is structured as follows: Section 1 introduce the research background and goal of the research, Section 2 begins with a brief review of e-learning, Section 3 reviews the DEA method, Section 4 explains the empirical analysis, and the Section 5 concludes our research results.

\section{Review of Literature}

Laurillard and Pachler (2007) defined m-learning is being the digital support of adaptive, investigative, communicative, collaborative, and productive learning activities in remote locations, proposes a wide variety of environments in which the teacher can operate. Yi et al. (2009) described that m-learning was an array of ways that people learn or stay connected with their learning environments including their classmates, instructors, and instructional resources while going mobile. Ozdamli et al. (2011) described that digital mobile e-learning (m-e-learning) was a kind of new learning model allowing learners to obtain learning materials anywhere and anytime using mobile technologies and the Internet. It is necessary that the elements of mobile learning are organized correctly and the interactions between the various elements are combined in an efficient and optimum way so that the mobile learning is successful and the implementation is efficient. As the use of mobile devices has proliferated, so has the concept that such devices may be useful in the process of teaching and learning (Khaddage, Muller, and Flintoff, 2016; Eppard, Nasser, and Reddy, 2016). We find the use of mobile technology in education provides educators with the opportunity to reimagine teaching and new learning model.

The "National Computer Usage Survey in 2007" compiled by the Executive Yuan also reported that the regions in Taiwan where the digital divide was the most prominent were characterized by a high proliferation of minorities, generation gap, rurality, and social disadvantage. Hence, the government has proposed three indicators for measuring the efforts to dissolve the digital divide and nurture a prospect of digitalization: 1. building the infrastructure, 2. opportunity, and 3. application. These three indicators could not only help analyze the current state of an information society and relevant trends, but also serve as key directions for efforts to dissolve the digital divide (Wang, 2010).

The digital mobile e-learning also offers an extensive variety of learning activities that 
support the learning process by means of motivation, control, ownership, fun and communication (Jones et al., 2006). When implementing mobile devices in an e-learning context, variables such as price, adaptability, and flexibility should not overshadow the fact that the adoption of a technology must be motivated by teaching scenarios, not merely factors such as technological functions (Lin, 2007). Therefore, the question of how to present the features of mobile devices in educational environments is extremely important. Furthermore, digital mobile e-learning emphasizes ubiquitous learning (u-learning), which is the notion that learning can occur at any time or place, not merely in schools or classrooms (Hwang et al., 2008).

Recent technological advancements have altered modern life and learning. Aided by information technology, learning has transcended the limit of time and space. The advantage of digital mobile e-learning lies in the design of both mobile devices and mobile learning environments, which differ from those common in traditional e-learning. For example, the traditional e-learning teaching model, which is primarily dependent on hardwired networking technologies, has evolved to a model based on wireless networking and mobile devices (Liu and Hwang, 2009). Moreover, the devices used in mobile e-learning are capable of supporting interactions between different learners and learning environments. Network-based technologies have pushed beyond traditional unidirectional learning, and have enabled interactive learning. With the aid of mobile technologies, learners can now access information and enjoy learning anytime and anyplace (Chen and Lin, 2007; Liu and Chen, 2009; Luo and Hsu, 2009).

On the other hand, Research indicates that the characteristics of mobile learning should be organized, and the way they are applied to mobile learning activities and the application methods and the duration of the application time should be planned well in advance. These reasons have learner, teacher, environment, content and assessment are basic elements of the complete mobile learning. The core characteristics of mobile learning are ubiquitous, portable size of mobile tools, blended, private, interactive, collaborative, and instant information. They enable learners to be in the right place at the right time, that is, to be where they are able to experience the authentic joy of learning. (Badri and El, 2012; Ozdamli and Cavus, 2011; Dickerson and Browning, 2009)

The above discussion suggests that digital mobile e-learning is a new model of learning that has gained considerable interest among industrial, governmental, and academic sectors. In their literature review, Hwang and $\mathrm{Wu}$ (2014) point out that among the seven renowned Social Sciences Citation Index (SSCI) databases on e-learning, approximately 214 studies published between 2008 and 2012 were related to digital mobile e-learning. Most of these studies indicate that the introduction of mobile e-teaching can indeed increase learning motivation among students.

In recent years, many scholars have employed Data Envelopment Analysis (DEA) to analyze operational efficiency and examine whether the widespread utilization of assessments can effectively enhance growth efficiency in order to improve operations management. According to the statistics, DEA has been applied empirically to more than one thousand cases in fields 
as diverse as transportation, educational administration, law, forest management, medicine, banking, military maintenance, and administration. Due to an abundance of prior research, the present study only reviewed relevant Taiwanese literature, which revealed that most studies focused on evaluating the operational performance of universities, high schools, middle schools, vocational schools, and national elementary schools (Wang et al., 1991; Chen, 1998; Gu, 1999; Liu, 2000; Hwang, 2001; Li, 2009; Hwang, 2012).

Our literature review revealed that the CCR and BCC models were most often used for performance evaluation. The inputs mainly included human resources (teachers, staff members, and students), financial resources, material resources (equipment and books), and space resources (campus size). The outputs mainly included teaching functions (the current number of students, graduates, and certificate holders), research functions (the number of research projects, awards, and published articles), education and employment opportunities (enrollment rates, number of graduates, number of dropouts, and number of people employed), student behavior (the number of students rewarded and/or punished), and other items (e.g., the number of times books or CDs were borrowed).

Education reforms coupled with innovative teaching which incorporates digital mobile e-learning can indeed increase students' interest in learning and their motivations. However, there have been limited related research published domestically or overseas and scanty theoretical discourses on topics such as whether the school that introduces digital mobile e-learning can capitalize on such initiatives to enhance teaching and increase the school's competitiveness and whether there are any differences in operational efficiency between county schools and city schools. Hence, what prompted the undertaking of the current study was to better understand the actual teaching in the field by analyzing appropriate cases where schools embarked on self-strengthening initiatives.

\section{Research Methodology}

The purpose of this research is to analyze whether really improve the efficiency of school management that implemented digital mobile e-learning and teaching in an attempt to determine whether the operational efficiencies of these schools were significantly improved following digital mobile e-learning introduction. The efficiencies of school management are measured by DEA. Furthermore, this study uses TRM to analyze that factors affecting the relative efficiencies of schools in various counties and cities by utilizing related factors as explanatory variables.

\subsection{Study Model}

\subsubsection{DEA}

The DEA model, proposed by Charnes et al.(1978) and known as CCR, assumes the DMUs to be assessed operate within a technology where efficient production is characterized by constant returns to scale(CRS).As above is obtained from the following Equation (1): 


$$
\begin{aligned}
& \operatorname{Max} h_{k}=\frac{\sum_{r=1}^{s} u_{r} y_{r k}}{\sum_{i=1}^{m} v_{i} x_{i k}} \\
& \text { s.t } \frac{\sum_{r=1}^{s} u_{r} y_{r j}}{\sum_{i=1}^{m} v_{i} x_{i j}} \leq 1 \quad, \quad j=1, \ldots, n \\
& u_{r}, v_{i} \geq \varepsilon>0, \quad r=1, \ldots \ldots \ldots, \quad i=1, \ldots \ldots . m
\end{aligned}
$$

where $x_{i j}$ is the amount of the i-th input to DMU j, $y_{r j}$ is the amount of the r-th output to DMU j; $u_{r}, v_{i}$ are called $\mathrm{r}$ virtual multiplier output and $\mathrm{i}$ virtual input multiplier; The value of $h_{k}$ obtained is termed the relative efficiency and is called the CCR efficiency, the $\varepsilon$ is a non-Archimedean positive element smaller any real number $\left(10^{-6}\right)$, the CCR model is called non-Archimedean small number.

Banker et al.(1984) modified this basic model to permit the assessment of the productive efficiency of DMUs where efficient production is characids by variable returns to scale (VRS).The VRS model, known as BCC, differs from the basic CCR model only in that in includes in the previous formulation the convexity constraint :

$$
\sum_{i=1}^{n} \lambda_{j}=1
$$

In summary, the following equation can be obtained for computing efficiencies:

Total $($ Technical) Efficiency $($ TE) $=$ Pure Technical Efficiency $($ PTE) $\times$ Scale Efficiency $($ SC)

\subsubsection{Tobit Regression Model (TRM)}

As the efficiency rate derived from DEA is often the function of influential variables such as DMU characteristics, region, attribute and other environmental variables are usually used to describe factors which could influence the efficiency of DMUs. In this study, such factors are not traditional inputs and are assumed to be outside the control of the DMUs. Since the sensitivity analysis proposed by Charnes, et al. (1994) to test the consistency of the results calculated based on DEA. However, this sensitivity analysis is still unable to show the degree of effect of input or output variables on the calculated efficiencies. As a result, we used the Tobit regression model belongs to the limited dependent variable or truncation econometrics model, with the nature of limited values of dependent variables relating to the actual observed explanatory variables (Celen, 2013).

The standard Tobit regression model (TRM, also known as truncated or censored regression model) indicated by Tobin's (1958) can be outlined as following Equation (2) for that $y_{i}^{*}$ is observed if $y_{i}^{*}>0$ and is not observed if $y_{i}^{*} \leq 0$.Then the observed $y_{i}$ will be defind as : 


$$
\begin{aligned}
& y_{i}=\left\{\begin{array}{cc}
y_{i=\beta x_{i}+u_{i}}^{*} & \text { if } y_{i}^{*}>0 \\
0 & \text { if } y_{i}^{*} \leq 0
\end{array}\right. \\
& u_{i \infty} \operatorname{IN}\left(0, \sigma^{2}\right)
\end{aligned}
$$

Where $u_{i \infty} \operatorname{IN}\left(0, \sigma^{2}\right), x_{i}$ and $\beta$ are vectors of explanatory variables and unknown parameters, respectively, while $y_{i}^{*}$ it is a latent variable and $y_{i}$ is the DEA efficiency scores. When the DEA scores are transformed, the coefficient of the Tobit regression model can be interpreted as if it is a coefficient of the maximum likelihood estimation (MLE). That is, it indicates the expected proportionate change of dependent variable with respect to one unit change in independent variable $\mathrm{Xi}$, holding other factors constant. In this study, we employ Tobit regression analysis to examine the effects of explanatory variables including digital mobile e-learning factors.

\section{Empirical Results and Analysis}

The empirical analysis of this study mainly comprised two parts: firstly, this section will adopt the DEA mode to analyze the relative efficiencies of schools analysis method. Followed by the application of the DEA model and Furthermore, this study applies Tobin regression model to analyze the factors which include digital mobile e-learning factors that affecting the relative efficiencies of schools in various counties and cities in Taiwan.

\subsection{Results of Efficiency Analysis for DEA Mode}

The efficiency analysis of this study mainly comprised three main sections. Section 1 describes the study objects and variable for inputs and outputs in this study. Section 2 presents data description and correlation analysis between inputs and outputs. Finally, Section 3 analyzes the efficiency analysis of DEA mode.

\subsubsection{Study Objects and Variable for Inputs and Outputs in This Study}

The study objects and variable selection for inputs and outputs in this study are described as follows:

\section{A. Study Objects}

This study aimed to analyze if the introduction of digital mobile e-learning increases schools' operational efficiency and if there are any differences in students' learning effectiveness in school between counties and cities. The study spanned four years and included periods before and after the introduction of digital mobile e-learning as well as periods during which such introduction continued. The names, attributes, and locations (county or city) of the above schools (study objects) are outlined in Table 1: 
Table 1. School Names and Characteristic

\begin{tabular}{llcl}
\hline NO & \multicolumn{1}{c}{ School name } & $\begin{array}{c}\text { mobile } \\
\text { e-learning(ME) }\end{array}$ & City name \\
& & & \\
\hline & & Yes & Taipei \\
\hline $\mathbf{1}$ & Taipei First Girls High School & Yes & Taipei \\
$\mathbf{2}$ & Taipei Municipal Fuxing Senior High School & Yes & Taipei \\
$\mathbf{3}$ & Taipei Municipal Lishan Senior High School & Yes & Taipei \\
$\mathbf{4}$ & Taipei Municipal Yang Ming Senior High School & Yes & Taipei \\
$\mathbf{5}$ & Taipei Municipal Zhong-Lun Senior High School & Yes & New Taipei \\
$\mathbf{6}$ & Juang Jing Vocational High School & Yes & New Taipei \\
$\mathbf{7}$ & Chi Jen Senior High School & Yes & I lan \\
$\mathbf{8}$ & National Lo-Tung Senior High School & Yes & Hualien \\
$\mathbf{9}$ & National Hualien Industrial Vocational Senior High School & & \\
\hline
\end{tabular}

Source: This Study

B. Variables Selection for Inputs and Outputs in This Study

The input and output variables for the above schools that introduced digital mobile e-learning and teaching are described as follows. Input variables included four items: the number of subjects and sessions, the number of teachers, the number of part-time teachers, and the number of faculty and staff. Output variables included three items: the total population of the school, the number of graduates, and the number of graduating classes. The selection of input and output variables was also predicated on the fact that DEA is a good methodology for evaluating efficiency. The study also formulated basic hypotheses for the model. If the conditions studied failed to match the hypotheses, the utility of the model would be compromised. Hence, when applying DEA, the number of Decision Making Units (DMUs) should be equal or greater than the multiplication of the number of inputs with the number of outputs. Otherwise, the efficiency estimated for each DMU through DEA would approximate the value of 1 and fail to discriminate among DMUs (Cooper et al., 2007). As this study adhered to this principle, operational efficiencies could be estimated and compared between schools that introduced digital mobile e-learning and those that did not.

In this paper, the input-output variables definitions of public and private vocational schools in the four cities, Taiwan are listed in Table 2 and Table 3. The including five input variables: academic department, number of full-time teachers, number of part-time teachers, and staff. There are three output variables: number of students, graduates student and classes. 


\section{Al Macrothink}

Table 2. Seven Major Indicator Definition for Inputs and Outputs

\begin{tabular}{llcl}
\hline NO & Indicators & Code & \multicolumn{1}{c}{ Definition } \\
\hline $\mathbf{1}$ & academic department & $x_{1}$ & Total academic department of the school. \\
$\mathbf{2}$ & number of full-time teachers & $x_{2}$ & The total number of full-time teachers. \\
$\mathbf{3}$ & number of part-time teachers & $x_{3}$ & The total number of part-time teachers. \\
$\mathbf{4}$ & staff & $x_{4}$ & The total number of staffs. \\
$\mathbf{5}$ & number of school students & $y_{1}$ & the number of school students \\
$\mathbf{6}$ & graduate student & $y_{2}$ & The number of graduate students. \\
$\mathbf{7}$ & classes & $y_{3}$ & The number of school classes. \\
\hline
\end{tabular}

Source: This Study

Table 3. DEA Model Input and Output Indicators Definitions

\begin{tabular}{llcl}
\hline NO & Indicators & Code & \multicolumn{1}{c}{ Definition } \\
\hline $\mathbf{1}$ & academic department & $x_{1}$ & Input Indicator \\
$\mathbf{2}$ & number of full-time teachers & $x_{2}$ & Input Indicator \\
$\mathbf{3}$ & number of part-time teachers & $x_{3}$ & Input Indicator \\
$\mathbf{4}$ & staff & $x_{4}$ & Input Indicator \\
$\mathbf{5}$ & number of school students & $y_{1}$ & Output Indicator \\
$\mathbf{6}$ & graduate student & $y_{2}$ & Output Indicator \\
$\mathbf{7}$ & classes & $y_{3}$ & Output Indicator \\
\hline
\end{tabular}

Source: This Study

\subsubsection{Data Descriptions and Correlation Analysis between Inputs and Outputs}

The section is divided into two main sections. Section 1 describes data descriptions. Section 2 presents the correlation analysis between inputs and outputs in this study.

\section{A. Data Descriptions}

Descriptive statistics were calculated. Ultimately, data was collected on several variables of interest for 27 out of the 9 schools for three years. The list of variables and their summary statistics are presented listed in Table 4.

Table 4. Descriptive Statistics

\begin{tabular}{llllll}
\hline & Minimum & Maximum & Mean & SD & variance \\
\hline academic department & 1.00 & 3.00 & 1.78 & 0.93 & 0.87 \\
number of full-time teachers & 70.00 & 195.00 & 143.11 & 38.97 & 1518.64 \\
number of part-time teachers & 1.00 & 73.00 & 17.70 & 19.62 & 385.06 \\
staff & 17.00 & 80.00 & 30.59 & 16.87 & 284.64 \\
number of school students & 723.00 & 4729.00 & 1962.33 & 1115.21 & 1243700.77 \\
graduate student & 294.00 & 1146.00 & 598.96 & 274.68 & 75447.96 \\
classes & 18.00 & 109.00 & 53.19 & 25.77 & 664.00 \\
\hline
\end{tabular}

Source: This Study 
B. Correlation Analysis between Inputs and Outputs

This study employed Pearson correlation analysis to first analyze the degree of correlation between input and output variables and removed variables with negative correlations. Another correlation analysis was then conducted to ensure positive correlations between the variables selected and adherence to the estimation principle of DEA.

Table 5. Correlation Test and Analysis

\begin{tabular}{lcccccc}
\hline & $\boldsymbol{x}_{2}$ & $\boldsymbol{x}_{3}$ & $\boldsymbol{x}_{\mathbf{4}}$ & $\boldsymbol{y}_{\mathbf{1}}$ & $\boldsymbol{y}_{2}$ & $\boldsymbol{y}_{\mathbf{3}}$ \\
\hline $\boldsymbol{x}_{2}$ & 1 & .421 & .528 & .819 & .825 & .815 \\
$\boldsymbol{x}_{3}$ & & 1 & .855 & .775 & .583 & .773 \\
$\boldsymbol{x}_{\mathbf{4}}$ & & & 1 & .792 & .567 & .761 \\
$\boldsymbol{y}_{\mathbf{1}}$ & & & & 1 & .905 & .978 \\
$\boldsymbol{y}_{2}$ & & & & & 1 & .867 \\
$y_{3}$ & & & & & & 1 \\
\hline
\end{tabular}

Source: This Study

Finally, the input variables chosen were the number of teachers, the number of part-time teachers, and the number of faculty and staff, while the output variables chosen were the total population of the school, the number of graduates, and the number of graduating classes. The results of final correlation analysis are displayed in Table 5.

\subsubsection{Efficiency Analysis}

Regarding efficiency analysis, Section 1 analyzes total efficiency, Section 2 indicates pure technical efficiency and Section 3 describes scale efficiency.

\section{A. Technical (Total) Efficiency (TE)}

As shown in Table 6 below after imported digital mobile e-learning. Since the introduction of digital mobile e-learning in 2012, only four out of the nine schools in four counties and cities reached an overall technology efficiency rate of "1" for three years in a row, including the Taipei First Girls' High School, Taipei Municipal Fuxing Senior High School, Taipei Municipal Lishan Senior High School, and Juang Jing Vocational High School. On the other hand, the remaining five schools failed to reach the efficiency rate of " 1 ", including the National Hualien Industrial Vocational High School, Chi Jen High School, National Lo-Tong Senior High School, National Yang Ming Senor High School, and Taipei Municipal Zhong-Lun High School. This result demonstrates that the introduction of digital mobile e-learning does not necessarily affect a school's operational efficiency in spite of the school's more robust connection to the network. For example, the operational efficiency of the Taipei Municipal Zhong-Lun High School is actually lower than that of other schools, despite the introduction of digital learning during 2013 and 2014. 
Table 6. Total Efficiency Analysis of High Schools in This Study

\begin{tabular}{llllll}
\hline DMU & 2013 & 2014 & 2015 & Average & Ranking \\
\hline 1 & 1 & 1 & 1 & 1 & 1 \\
2 & 1 & 1 & 1 & 1 & 1 \\
3 & 0.838 & 0.848 & 0.796 & 0.827 & 8 \\
4 & 1 & 1 & 0.955 & 0.985 & 5 \\
5 & 1 & 1 & 1 & 1 & 1 \\
6 & 1 & 0.784 & 0.758 & 0.847 & 7 \\
7 & 1 & 1 & 0.797 & 0.932 & 6 \\
8 & 0.578 & 0.637 & 0.985 & 0.733 & 9 \\
9 & 1 & 1 & 1 & 1 & 1 \\
\hline
\end{tabular}

Source: This Study

\section{B. Pure Technical Efficiency (PTE)}

As shown by the data in Table 7 on pure technical efficiency, the efficiency rates of five out of the nine schools in four counties and cities that introduced digital learning for three years in a row reached "1", including the Taipei First Girls' High School, Taipei Municipal Fuxing Senior High School, Chi Jen High School, Taipei Municipal Lishan Senior High School, and Juang Jing Vocational High School. All these schools are located in Taipei City or New Taipei City. This result shows that these schools utilized their resources effectively and did not need to make any further adjustment or improvement, when external factors were excluded. On the other hand, the efficiency rates of the remaining four schools were below " 1 ", including the National Hualien Industrial Vocational High School, National Lo-Tong Senior High School, National Yang Ming Senor High School, and Taipei Municipal Zhong-Lun High School. These schools all needed to make further improvement or adjustment, when external factors were excluded. This result shows that differentials in resources do exist across counties and cities, which could impact the pure technical efficiency of schools. This explains why the efficiency rates of some schools are lower than " 1 ," that is, because of the county or city where they are located.

\section{Scale Efficiency(SE)}

As shown by the results in Table 8 on scale efficiency, the efficiency rates of four out of the nine schools in four counties and cities that introduced digital learning for three years in a row reached "1", including the Taipei First Girls' High School, Taipei Municipal Fuxing Senior High School, Taipei Municipal Lishan Senior High School, and Juang Jing Vocational High School. All these schools are located in Taipei City or New Taipei City. On the other hand, the five remaining schools failed to reach the efficiency rate of " 1 ", including the National Hualien Industrial Vocational High School, Chi Jen High School, National Lo-Tong Senior High School, National Yang Ming Senor High School, and Taipei Municipal Zhong-Lun High School. The Taipei Municipal Zhong-Lun High School was the only school with declining returns to scale. Hence, in order to optimize its scale of operation, the school needs to reduce its scale. Too many resources may have rendered the school's operation inefficient. With increasing returns to scale, the other schools need to expand their scales of 
operation in order to reach the optimal scale efficiency. They have not received sufficient resources, which also renders schools' operations inefficient.

Table 7. Pure Technical Efficiency Analysis High Schools in This Study

\begin{tabular}{llllll}
\hline DMU & 2013 & 2014 & 2015 & Average & Ranking \\
\hline 1 & 1 & 1 & 1 & 1 & 1 \\
2 & 1 & 1 & 1 & 1 & 1 \\
3 & 0.850 & 0.856 & 0.826 & 0.845 & 9 \\
4 & 1 & 1 & 1 & 1 & 1 \\
5 & 1 & 1 & 1 & 1 & 1 \\
6 & 1 & 0.917 & 0.869 & 0.929 & 7 \\
7 & 1 & 1 & 0.956 & 0.985 & 6 \\
8 & 0.761 & 0.774 & 1 & 0.845 & 8 \\
9 & 1 & 1 & 1 & 1 & 1 \\
\hline
\end{tabular}

Source: This Study

Table 8. Scale Efficiency Analysis of High schools

\begin{tabular}{lllllll}
\hline DMU & 2013 & 2014 & 2015 & Average & returns to scale (RTS) & Ranking \\
\hline 1 & 1 & 1 & 1 & 1 & Constant & 1 \\
2 & 1 & 1 & 1 & 1 & Constant & 1 \\
3 & 0.987 & 0.991 & 0.963 & 0.980 & Increasing & 9 \\
4 & 1 & 1 & 0.954 & 0.985 & Increasing & 1 \\
5 & 1 & 1 & 1 & 1 & Constant & 1 \\
6 & 1 & 0.855 & 0.871 & 0.909 & Increasing & 7 \\
7 & 1 & 1 & 0.833 & 0.944 & Increasing & 6 \\
8 & 0.760 & 0.823 & 0.985 & 0.856 & Decreasing & 8 \\
9 & 1 & 1 & 1 & 1 & Constant & 1 \\
\hline
\end{tabular}

Source: This Study

\subsection{Results of Tobit Regression Model (TRM)-Explaining the Determinants Affecting} Technical Efficiency

To discuss the results for Tobit Regression Analysis. Section 1 describes the model setups including regression variable and parameter setting for TRM. Section 2 discusses the empirical results of TRM.

The reason for we used Tobit regression application is that when the dependent variable is continuous but constrained by something, the Tobit regression model assumes truncated normal distribution in place of normal distribution and employs the maximum likelihood estimation (MLE) method. Since the DEA scores have lower and upper limits, there may be a truncated bias in the OLS regression model. This is why we used the Tobit regression model 


\section{Macrothink}

(Tobin, 1958) with MLE rather than the OLS estimation.

Based on the related theories and literature provided useful information in this study, it is indicates that the variables usually be used related researches, and we focus the major variables that relate to the determinants of mobile digital e-learning. Basic model setups can be described as follows:

\section{A. Model Setups}

Basic model setups can be described as following Equation (4):

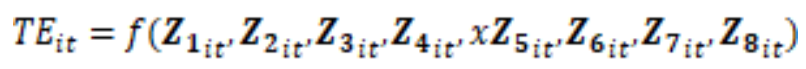

The statistical model can be written as follows (Equation (5)):

$$
T E_{\text {it }}=\beta_{0}+\beta_{1} Z_{1_{\text {it }}}+\beta_{2} Z_{2_{i t}}+\beta_{9} Z_{3_{i t}}+\beta_{4} Z_{4}+\beta_{5} Z_{5_{i t}}+\beta_{6} Z_{6 \text { it }}+\beta_{7} Z_{7_{i t}}+\beta_{8} Z_{8_{i t}}+\varepsilon_{i t}
$$

The theoretically expected signs of the coefficients are:

$\beta_{1}>0, \beta_{2}>0, \beta_{3}>0, \beta_{4}>0, \beta_{5}>0, \beta_{6}>0, \beta_{7}>0, \beta_{8}>0$

Where

$T E_{i t}:$ Technical Efficiency for management of School i during the period 2013 to 2015

$Z_{1_{i t}}:$ School size (total numbers of school students) of School i

$Z_{2_{i t}}:$ Teacher-student ratio (average number of students per teacher members) of School i

$Z_{3_{\text {it }}}:$ The total number of tablet PC of School i

$Z_{4_{i t}}$ : Technical teacher ratio (measured by the ratio for the numbers of technicians as consultants for teaching tablet PC knowledge to total number of teachers in school) of School i

$Z_{5_{i t}}:$ Total equipment expenses associated with tablet PC of School i

$Z_{6_{i t}}:$ School location dummy: in the northern area: 1 , other areas: 0

$Z_{7_{\text {it }}}$ : School attribute dummy: public high schools: 1, private high schools: 0

$Z_{\mathbf{8}_{\text {it }}}:$ School attribute dummy: senior High School: 1, vocational high schools: 0

$\varepsilon_{i t}:$ Disturbance terms, $\varepsilon_{i t}$ iiid $N\left(0, \sigma^{2}\right)$

B. Tobit Regression Results: Explaining the Determinants Affecting Technical Efficiency

In this study, we use panel data (time series and cross-section data) to estimate how each factor including digital mobile e-learning affecting operational efficiency. Panel data may have group effects, time effects or both. These effects are either fixed effect or random effect. 
A fixed effect model assumes differences in intercepts across groups or time periods, whereas a random effect model explores differences in error variances. The Hausman specification test compares the fixed versus random effects under the null hypothesis that the individual effects are uncorrelated with the other repressors in the model (Hausman, 1978). Prior the estimation for Equations (5), the Hausman test ( $p$ value $=0.0041,0.0024$ ) shows that the $p$ value is less than 0.05 which is significant. This implies that the null hypothesis that random effect model which consistent and efficient is rejected. Therefore, the fixed effect model is preferred model and will be used in this study. This research investigates the factors affecting the TE based on a sample of 27 schools over the period 2012-2015. Table 9 reports the regression results through the maximum likelihood estimation (MLE) for the dynamic panel data model with fixed effect to analyze the factors affecting the technical efficiency (TE).

As indicated in Table 9, we can find firstly that school size $\left(\beta_{1}=2.167\right)$, teacher - student ratio ( $\left.\beta_{2}=-0.45\right)$, tablet PC numbers $\left(\beta_{3}=0.038\right)$, technical teacher ratio $\left(\beta_{4}=0.0024\right)$, The total equipment expenses associated with tablet PC $\left(\beta_{5}=-0.001\right)$ and School attribute $\left(\beta_{g}=0.067\right)$ are important determinants for affecting efficiency of school management .

Table 9. The Determinants Affecting Technical Efficiency

\begin{tabular}{clllll}
\hline Variable & & $\beta$ (Beta) & Std. Error & t-value & P value. \\
\hline Constant & $\beta_{0}$ & $-7.790^{* * *}$ & 1.0686 & -7.29 & 0.000 \\
$Z_{1}$ & $\beta_{1}$ & $2.176^{* * *}$ & 0.2506 & 8.68 & 0.000 \\
$Z_{2}$ & $\beta_{2}$ & $-0.450^{* * *}$ & 0.0471 & -9.56 & 0.000 \\
$Z_{3}$ & $\beta_{3}$ & $0.038^{* * *}$ & 0.0043 & 8.90 & 0.000 \\
$Z_{4}$ & $\beta_{4}$ & $0.0024 * * *$ & 0.0004 & 5.53 & 0.000 \\
$Z_{5}$ & $\beta_{5}$ & $-3.6500 \times^{10^{-5}} * * *$ & $4.100 \times^{10^{-6}}$ & -8.88 & 0.000 \\
$Z_{6}$ & $\beta_{6}$ & -0.047 & 0.0301 & -1.57 & 0.115 \\
$Z_{7}$ & $\beta_{7}$ & 0.038 & 0.0210 & 1.85 & 0.064 \\
$Z_{8}$ & $\beta_{8}$ & $0.073^{* * *}$ & 0.0240 & 3.00 & 0.003 \\
\hline Likelihood & & & $39.82^{* * *}$ & & \\
Wald Test & & $14.27^{* * *}$ & & \\
Durbin Watson Test & \multicolumn{5}{c}{1.927} \\
White Test & & 9.08 & & \\
ARCH Test & & 4.18 & & \\
\hline
\end{tabular}

Source: This Study

Note: $* \mathrm{p}<0.10 ; * * \mathrm{p}<0.05 ; * * * \mathrm{p}<0.001$

The results

(1) $\operatorname{School} \operatorname{size}\left(Z_{1}\right)$

According to the empirical results shown in Table 9, the effect of school size $\left(\beta_{1}=2.176\right)$ on school's operational efficiency is significant at $1 \%$ level and positive relationship as we expected. It implies that the larger the school, the economics of scale can accomplished when 
outputs expand (such as teaching functions, research functions and education or employment opportunities (enrollment rates)) and then cause school's operational efficiency. The studies of Dickerson and Browning (2009) justified that a successful digital mobile e-learning integration, increasing more persons such as school students to apply this digital mobile e-learning is important. Thus, an increase in the number of school students may also add to the school's operational efficiency.

(2) Teacher-student ratio $\left(\boldsymbol{Z}_{2}\right)$

Based on empirical results shown in Table 9. The effect of the teacher-student ratio $\left(\beta_{2}=\right.$ -0.450 ) on school's operational efficiency is significant $1 \%$ level and negative value. One of the main reasons that the low fertility problem in Taiwan, the number of students (output variable) decreased and overestimate the teacher-student ratio. i e., class size decreases and leads to too many teachers as input in each class. Therefore, resource misallocation in teachers and students and the cost per teacher over counts and hence reduce the school's operational efficiency. Previous research of Badri and El (2012) supports our findings.

\section{(3) Tablet PC numbers $\left(\boldsymbol{Z}_{\mathbf{3}}\right)$}

As can be seen that the results shown in Table 9. The effect of tablet PC numbers $\left(\beta_{3}=0.038\right)$ on school's operational efficiency in the model have significant at $1 \%$ level and positive relationship as we expected. The innovative teaching to affect school efficiency through using digital mobile e-learning by Tablet PC enable learners to be in the right place at the right time, that is, to be where they are able to experience the authentic joy of learning and attract students join. As results, the more Tablet PC numbers to be applied in high school will cause the school's operational efficiency. Our result is consistent with Ozdamli and Cavus (2011) justified that a successfully attract students to join digital mobile e-learning and then cause school's operational efficiency.

(4) Technical teacher ratio $\left(\boldsymbol{Z}_{\mathbf{4}}\right)$

According to the estimated results shown in Table 9. The effect of technical teacher ratio (measured by the ratio for the numbers of technicians as consultants for teaching tablet PC knowledge total number of teachers in school) $\left(\beta_{4}=0.0024\right)$ on school's operational efficiency in the model have significant at $1 \%$ level and positive relationship as we expected. The transition of the media formats changed the role of the average teacher from being an expert towards being a presenter of the expertise of others. In these settings, the role of the teachers needs to change from the presenter of expert knowledge to a moderator of opposing positions. In this role, teachers act as technicians as consultants for teaching tablet PC knowledge need to be able to identify the students' interests, relate these interests to the topic related learning goals, and offer opportunities to reach these goals that are related to the specific conditions a learner is in. Thus, an increase in the technical teacher ratio may also add to the, even more, school students to apply this digital mobile e-learning program, when ratio for the numbers of technicians as consultants for teaching tablet PC knowledge total number of teachers in school expand, they are able to cause school's operational efficiency. The study of Ozdamli 
and Cavus (2011) also supports our analysis that a successful digital mobile e-learning integration, to induce increasing more persons learn such as school students to apply this digital mobile e-learning.

(5) Total equipment expenses associated with tablet PC $\left(\boldsymbol{Z}_{5}\right)$

Based on the estimated results shown in Table 9. The effect $\left(\beta_{5}=-3.6500 \times 10^{-5}\right)$ of total equipment expenses associated with tablet PC on school's operational efficiency in the model have significant at $1 \%$ level and negative relationship. In general, mobile e- learning (mobile-e-learning) as a kind of learning model allowing learners to obtain learning materials anywhere and anytime. In addition, as indicated by the studies of Ozdamli and Cavus (2011), the characteristics of mobile learning should be organized, and the way they are applied to mobile learning activities and the application methods and the duration of the application time should be planned well in advance. The internet and network equipment or device need to be constructed well and completely. Our empirical results indicate that the total equipment expenses associated with tablet PC have a negative influence on school management efficiency due to the increasing costs for furnishing the related internet and network equipment or device to facilitate for teaching and learning among teachers and students by digital mobile e-learning.

(6) School location: $\left(\boldsymbol{Z}_{6}\right)$

The effect of school location $\left(\beta_{6}=-0.047\right)$ on school's operational efficiency in the model has non-significant at $1 \%$ level shown in Table 9 . The first reason is that the study examples of our case study are quite smaller. Hence, the effect of school location on school's operational efficiency may not significant. In this study, on the other hand, in order to promote digital mobile e-learning by incorporating e-teaching platforms. For many years, high schools in various counties and cities in Taiwan have gradually and almost introduced education reforms and innovative teaching through mobile digital e-learning. This may be also one of the reasons that the effect of school location on school's operational efficiency may not be significant. Mainly, the degree of school's operational efficiency also need to be taken into account their school attributes such as equipment, teaching quality, management decisions and etc.(Liu et al., 2016).

(7) School attribute $\left(\boldsymbol{Z}_{7}\right)$

The effect of school attribute $\left(\beta_{1}=0.038\right)$ on school's operational efficiency in this study have significant at $1 \%$ level and positive relationship as indicated in Table 9. In this study, we consider whether the public or private school has different operational efficiency. Our empirical results depict that operational efficiency of public school is better than that of private school. The public school accessory equipment comes from the budget of the central government, but the private school accessory equipment of budget comes from oneself school. Teaching quality in public high school, for example, easier apply mobile e-learning environments which utilizes the latest technologies to bring an interactive learning environment into learning and teaching activities. This may also cause the public school to 
have better school's operational efficiency (Liu et al., 2016).

(8) School high-vocational attribute $\left(Z_{8}\right)$

The effect of school high-vocational attribute $\left(\beta_{8}=0.073\right)$ on school's operational efficiency in this study have significant level at $1 \%$ and positive relationship as indicated in Table 9. In this study, we consider whether the high or vocational school has different operational efficiency. Our empirical results depict that operational efficiency of high school is better than that of vocational school on the school equipment aspect. The high school accessory equipment mostly comes from the budget of the central government, but the vocational school accessory equipment of budget comes from oneself school. Teaching quality in public high school, for example, easier applies mobile e-learning environments which utilizes the latest technologies to bring an interactive learning environment into learning and teaching activities. This may also cause the high school to have better school's operational efficiency (Liu et al., 2016).

C. goodness-of-fit of the estimated model

Based on statistical analysis, the empirical results are good fit with log likelihood 39.82 in model, Wald test statistic $14.27^{* * *}$ in model. Durbin Watson Test statistic equal 1.927, White statistic 9.08 and ARCH Test 4.18 in model respectively (Table 9). Both show neither autocorrelation nor heteroscedasticity in estimated error term. This information also indicates that our discussions above on these determinants affecting operational efficiencies of the high schools in this study would be more accurate and appropriate.

\section{Concluding Remarks}

In this study, we firstly apply data envelopment analysis (DEA) to analyze the operational efficiency of high school in Taiwan and then justify whether mobile digital learning can affect a school's operational efficiency by Tobin regression model (TRM).

Based on our empirical results from DEA method, only four out of the nine schools in four counties and cities reached an overall technical efficiency (TE) rate of "1" for three years in a row, including the Taipei First Girls' High School, Taipei Municipal Fuxing Senior High School, Taipei Municipal Lishan Senior High School, and Juang Jing Vocational High School. On the other hand, the five remaining schools failed to reach the efficiency rate of " 1 ", including the National Hualien Industrial Vocational High School, Chi Jen High School, National Lo-Tong Senior High School, National Yang Ming Senor High School, and Taipei Municipal Zhong-Lun High School. Regarding to the measurement of pure technical efficiency (PTE), the efficiency rates of five out of the nine schools in four counties and cities that introduced digital learning for three years in a row reached " 1 ", including the Taipei First Girls' High School, Taipei Municipal Fuxing Senior High School, Chi Jen High School, Taipei Municipal Lishan Senior High School, and Juang Jing Vocational High School. All these schools are located in Taipei City or New Taipei City. As for the measurement for scale efficiency(SE), the efficiency rates of four out of the nine schools in four counties and cities that introduced digital learning for three years in a row reached "1", including the Taipei First 


\section{MInstitute Macrothink $^{m}$}

Girls' High School, Taipei Municipal Fuxing Senior High School, Taipei Municipal Lishan Senior High School, and Juang Jing Vocational High School. All these schools are located in Taipei City or New Taipei City

In this study, we also apply the Tobit Regression Model (TRM) to find that the school size, teacher-student ratio, tablet PC numbers, technical teacher ratio, the total equipment expenses associated with tablet PC and School High-Vocational attribute are important determinants for affecting efficiency of school management. Our empirical results further demonstrate and justify that School size, especially the numbers of technical teachers in teaching or consulting about digital mobile e-learning knowledge and numbers of Tablet PC (proxy for digital mobile e-learning) to affect efficiency of school management. In order to increase students learning effectiveness to enhance the school's operational efficiency in this study, it is necessary to first add school size, Tablet PC numbers and technical teachers. In general, an increase in the technical teacher ratio may also add to the, even more, school students to apply this digital mobile e-learning program, when ratio for the numbers of technicians as consultants for teaching tablet PC knowledge total number of teachers in school expand, they are able to cause school's operational efficiency. However, it should be noted that total equipment expenses associated with tablet PC has a small negative influence on school management efficiency due to the increasing costs for furnishing the related internet and network equipment or device to facilitate for teaching and learning among teachers and students by digital mobile e-learning. The effect of school public-private attribute on school's operational efficiency (which is considered by total efficiency (TE)) is not significant but positive relationship; however the effect of school high-vocational attribute on school's operational efficiency have significant and positive relationship in this study. The above results of this research can also be the reference for educational authorities when formulating policies and regulations for promoting digital mobile e-learning in high school in Taiwan.

Lastly, the conclusions and recommendations presented here are based on the models constructed, sample data collected, and research methodologies employed for this study. Hence, it is necessary to take into consideration the current situation and changes in the environment that are impacting the public and private high schools and vocational schools in the Taiwan District, so any application of our findings can be further tailored to yield more accurate conclusions.

\section{References}

Banker, R. D., Charnes, A., \& Cooper, W. W., (1984). Some Models for the Estimation of Technical and Scale Inefficiencies in Data Envelopment Analysis. Management Science, 30, 1078-1092. https://doi.org/10.1287/mnsc.30.9.1078

Badri, M. A., \& E. 1. Mourad, T. (2012). Determinants of School Efficiencies in Abu Dhabi Using DEA. In International Conference on Management and Education Innovation IPEDR (37).

Celen, A. (2013). Efficiency and productivity (TFP) of the Turkish electricity distribution 
companies: An application of two-stage (DEA and Tobit) analysis. Energy Policy, 63, 300-310. https://doi.org/10.1016/j.enpol.2013.09.034

Charnes, A., Cooper, W. W., \& Rhodes, E. (1978). Measuring the Efficiency of Decision Making Units. European journal of operational research, 2(6), 429-444. http://doi.org/10.1016/0377-2217(78)90138-8

Charnes, A., Cooper, W. W., Lewin, A. Y., \& Seiford, L. M. (Eds.). (2013). Data envelopment Analysis: Theory, Methodology, and Applications. Springer Science \& Business Media.

Chen, R. F. (1998). Evaluation of Educational Quality in Universities and Colleges in Taiwan Using Data Envelopment Analysis. Academic Journal of Kaohsiung Institute of Science and Technology, 28, 227-238.

Chen, C. Y., \& Lin, H. C. (2007). Applications and Analysis of Mobile Learning in Education. Living Technology Education, 40, 31-38.

Chiang, W. M. (2009). Impact of Low Birth Rate on High School Education and Recommendations. Secondary Education Monthly, 60(1), 26-34.

https://doi.org/ 10.1177/0013124510370946

Cooper, J. O., Heron, T. E., \& Heward, W. L. (2007). Applied Behavior Analysis (2nd Ed.). Upper Saddle River: NJ

Dickerson, J., Williams, S., \& Browning, J. B. (2009). Scaffolding Equals Success in Teaching Tablet PCs. The technology teacher, 68(5), 16-21.

Eppard, J., Nasser, O., \& Reddy, P. (2016). The Next Generation of Technology: Mobile Apps in the English Language Classroom. International Journal of Emerging Technologies in Learning, 11(4), 21-27. https://doi.org/10.3991/ijet.v11i04.5293

Gu, Z. Y. (1999). A study on the Productivity Assessment and Integration Model of Resource Allocation in Higher Education Units. Journal of Management and Systems, 6(3), 347-364. https://doi.org/10.1080/0260293990240302

Hwang, J. X. (2001). Evaluating the Efficiencies of National High Schools in Taiwan: Application of Data Envelopment Analysis (MA Thesis - unpublished), Chiayi City: National Chung Cheng University.

https://doi.org/ 10.1109/IIAI-AAI.2013.85

Hwang, G. J., Tsai, C. C., \& Yang, S. J. H. (2008). Criteria, Strategies and Research issues of Context-aware Ubiquitous learning. Educational Technology and Society, 11(2), 81-91.

Hwang, Y. X. (2012). Comparative Analysis of the Operational Performance of Public and Private High Schools, Middle Schools, and Vocational Schools with Schools in the Sindian District of New Taipei City as Examples (MA Thesis - unpublished), Taichung: Asia University.

Hwang, G. J., \& Wu, P. H. (2014). Applications, Impacts and Trends of Mobile Technology-Enhanced Learning: a Review of 2008-2012 Publications in Selected SSCI 


\section{MInstitute Macrothink}

Journals. International Journal of Mobile Learning and Organization, 8(2), 83-95. https://doi.org/10.1504/IJMLO.2014.062346

Jones, A., Issroff, K., Scanlon, E., Clough, G., \& McAndrew, P. (2006). Using Mobile Devices for Learning in Informal Settings: Is it motivating? Paper to be presented at IADIS International Conference Mobile Learning, 14-16 July 2006, Dublin, IADIS Press, 251-255.

Khaddage, F., Müller, W., \& Flintoff, K. (2016). Advancing Mobile Learning in Formal and Informal Settings Via Mobile App Technology: Where to from Here, and How? Educational Technology and Society, 19(3), 16-27.

Kattayat, S., Josey, S., \& JV, A. (2017). Mobile Learning Apps in Instruction and Students Achievement. International Journal of Interactive Mobile Technologies, 11(1), 143-147. https://doi.org/10.3991/ijim.v11i1.6420

Laurillard, D., \& Pachler, N. (2007). Pedagogical forms of mobile learning: framing research questions. In N. Pachler (Ed.), Mobile learning: towards a research agenda (33-54). London: WLE Centre, IOE.

Liu, H. H., Kuo, F. H., \& Li, L. H. (2016). The Operating Efficiency of Vocational and Senior High Schools in Xindian District of New Taipei City: Three Envelopment Models in DEA. International Business Research, 9(11), 116-125. https://doi.org/10.5539/ibr.v9n11p116

Liu, M. C. (2000). A Study on the Assessment of the Management Efficiencies of Education at Vocational High Schools in Taiwan: Applied Analysis of the DEA Model (MA Thesis unpublished). Nantou County: National Chi Nan University.

Lin, Q. B. (2007). Activity Design and Development for the Use of an Electronic Assistant Device in Collaborative Language Learning. Report on the Achievements of the Monographic Research Project by the National Science Council of the Executive Yuan.

Li, C. Y. (2009). Assessment of the Operational Efficiency of Vocational High Schools: Data Envelopment Analysis. Xiong Gong Academic Journal.

Liu, C. H., \& Ch'en, W. Y. (2009). Research on Mobile Learning Experimental Systems. Paper Presented at the Conference of Digital Technology and Innovation Management, Taipei, Huafan University.

Liu, G. Z., \& Hwang, G. J. (2009). A key Step to Understanding Paradigm Shifts in e-learning: towards context-aware ubiquitous learning. British Journal of Educational Technology, 40(6), E1-E9.

Luo, C. C., \& Hsu C. Y. (2009). Reducing the Digital Divide Between Cities and Rural Areas: From Digital Learning to Mobile Learning. Living Technology Education, 42, 96-108. https://doi.org/10.1111/j.1467-8535.2009.00976.x

Ozdamli, F., \& Cavus, N. (2011). Basic Elements and Characteristics of Mobile Learning. 
$\begin{array}{llll}\text { Procedia-Social and Behavioral } & \text { Sciences, } & 28, & 937-942 .\end{array}$ https://doi.org/10.1111/j.1467-8535.2009.00976.x

Tobin, J. (1958). Estimation of Relationships for Limited Dependent Variables. Econometrical: journal of the Econometric Society, 24-36. https://doi.org/10.2307/1907382

Valdmanis, V. (1992). Sensitivity analysis for DEA models: An empirical example using public vs. NFP hospitals. Journal of Public Economics, 48(2), 185-205. https://doi.org/10.1016/0047-2727(92)90026-C

Wang, G. M., \& Gu, Z. Y. (1991). A Study on the Application of DEA in Educational Assessment. Modern Education, 6(1), 118-127.

Wang, C. H. (2010). Examination and Management of the Digital Divide in Taipei County. Journal of INGO, 1, 1-48.

Yi, C.C., Liao, W. P., Huang, C.F., \& I. H., Hwang. (2009). Acceptance of Mobile Learning: a Respecification and Validation of Information System Success. In Proceedings of World Academy of Science. Engineering and Technology, 41, 2070-3740.

\section{Copyright Disclaimer}

Copyright for this article is retained by the author(s), with first publication rights granted to the journal.

This is an open-access article distributed under the terms and conditions of the Creative Commons Attribution license (http://creativecommons.org/licenses/by/3.0/). 